\title{
ANALISIS POSTUR KERJA OPERATOR DENGAN METODE RULA DI AREA GAS CUTTING
}

\author{
Irwan Pegiardi, Firdanis Setyaning Handika, Supriyadi \\ Program Studi Teknik Industri, Fakultas Teknik, Universitas Serang Raya \\ Email: irwanpegiardi@yahoo.co.id; firdanishandika@gmail.com; supriyadimti@gmail.com
}

\begin{abstract}
Abstrak - Area gas cutting mempunyai beberapa pekerjaan yang berisiko terhadap operator seperti aktivitas dengan jongkok, pekerjaan dengan posisi membungkuk. Penelitian ini bertujuan untuk mengetahui risiko pekerjaan pada area gas cutting sebagai dasar perbaikan postur kerja. Metode yang digunakan adalah RULA (Rapid Upper Limb Assessment) merupakan suatu metode penelitian untuk menginvestigasi gangguan pada anggota badan bagian atas. Dengan mengukur nilai skor grup A dan nilai skor grup B. Berdasarkan hasil penelitian nilai RULA pada proses mengoperasikan mesin dengan posisi duduk dengan skor 3. membersihkan sisi plate hasil pemotongan dengan posisi membungkuk dengan skor 5, dan skor tertinggi 6 pada proses menggerinda sisi plate hasil pemotongan. Untuk mengurangi rasa sakit pada leher, batang tubuh, dan lengan, sebaiknya para operator tidak melakukan postur kerja yang menyebabkan rasa sakit pada bagian tubuh tersebut dalam waktu yang lama.
\end{abstract}

Kata kunci: Beban Kerja; Gas Cutting; RULA (Rapid Upper Limb Assessment)

\begin{abstract}
The gas cutting area has several jobs that are risky to the operator, such as activities with squatting, bending positions. This study aims to determine the risk of work in the gas cutting area as a basis for improving work posture. The method used is RULA (Rapid Upper Limb Assessment) is a research method for investigating disorders of the upper limbs. By measuring the group A score and group $B$ score. Based on the results of the RULA value in the process of operating the machine with a sitting position with a score 3. clearing the cutting plate with a bent position with a score of 5 , and the highest score 6 in the grinding plate cutting. To reduce pain in the neck, torso, and arms, operators should not do work postures that cause pain in the body for a long time.
\end{abstract}

Keywords: Gas Cutting; RULA (Rapid Upper Limb Assessment); Workload

\section{PENDAHULUAN}

Pekerja yang melakukan aktivitas dengan beban yang berat serta tidak ditunjang dengan peralatan yang safety membutuhkan tenaga berlebih dan berisiko pada postur kerja yang tidak nyaman seperti bekerja dengan jongkok, membungkuk dan membawa beban adalah merupakan risiko terjadinya keluhan musculoskeletal dan kelelahan dini. Postur kerja yang salah sering diakibatkan oleh letak fasilitas yang kurang sesuai dengan anthropometri. operator sehingga mempengaruhi kinerja operator. Postur kerja yang tidak safety seperti bekerja dalam posisi berdiri, membungkuk, jongkok, mengangkat beban tanpa bantuan alat maupun material handling lainnya dalam jangka waktu lama bisa berakibat pada keluhan sakit salah satu anggota tubuh. Kegiatan ini secara jangka panjang menjadi salah satu faktor terjadinya risiko kecelakaan kerja seperti sakit pinggang, maupun punggung (Listiarini, Widjasena, \& Wahyuni, 2016). Kelelahan dini pada pekerja juga dapat menimbulkan penyakit akibat kerja dan kecelakaan kerja yang mengakibatkan cacat bahkan kematian.

Plate rolling Department memiliki tiga ruang utama dalam kegiatan produksi, yaitu Mill Line, Shearing Line dan Finishing Line. Kegiatan produksi Plate rolling Department adalah pengolahan dan pemotongan dari sebuah slab, menjadi mother plate lalu menghasilkan produk jadi yang berkualitas tinggi. Pengolahan slab berada di Mill Line dan pemotongan mother plate berada di bagian shearing dan finishing. Pemotongan mother plate menggunakan beberapa mesin yang terdapat pada bagian shearing dan finishing. Shearing memiliki 3 mesin yaitu Crop shear, Double side shear dan Dividing shear sedangkan mesin pada bagian finishing yaitu gas cutting. Mesin-mesin tersebut 
digunakan untuk proses pemotongan mother plate sehingga menghasilkan produk plate dengan dimensi sesuai permintaan konsumen. Dengan adanya mesin tersebut dapat membantu kelancaran produksi.

Namun pada kenyataannya perusahaan sulit mencapai produktivitas dan efisiensi yang tinggi. Salah satu faktornya adalah dari segi operator, dimana operator mengalami ketidaknyamanan dalam bekerja, gangguan kesehatan maupun penyakit yang diakibatkan beban kerja berlebih. Risiko tersebut terjadi karena adanya sumber bahaya akibat dari aktivitas kerja seperti mengangkat atau menurunkan produk secara manual, bekerja dengan posisi jongkok atau berdiri, bekerja dalam dalam lingkungan yang tidak safety maupun kegiatan lain yang berisiko menyebabkan keluhan dan kecelakaan kerja.

Metode yang biasa digunakan untuk menganalisa keluhan tubuh bagian atas adalah metode RULA (Rapid Upper Limb Assessment). Metode RULA merupakan metode survei yang untuk digunakan dalam investigasi ergonomi di tempat kerja yang memiliki risiko akibat kerja (Ansari \& Sheikh, 2014; McAtamney \& Corlett, 1993) dengan memakai diagram dari postur tubuh dan tabel skor untuk mengevaluasi faktor risiko tersebut (Budiman \& Setyaningrum, 2012; Nuryaningtyas \& Martiana, 2014). Aplikasi RULA dalam beberapa kasus dalam kegiatan mampu memperbaiki postur kerja yang mampu mengurangi keluhan sakit yang pernah terjadi (Agustina \& Maulana, 2012; Correia, Yusuf, \& Simanjuntak, 2016; Nugraha, Astuti, \& Rahman, 2013).

Berdasarkan penerapan metode RULA yang telah berhasil, penelitian ini bertujuan mengevaluasi postur kerja operator di area cutting gas berdasarkan metode RULA. Hasil skor RULA sebagai bahan evaluasi untuk mengurangi keluhan sakit operator..

\section{METODE PENELITIAN}

Penelitian dilakukan pada operator Gas Cutting dengan jumlah 20 operator menggunakan metode RULA. Perhitungan metode RULA ini meliputi skor grup A dan skor grup B dimana data-data yang diperoleh melalui Hasil Standard Nordic Questionnaire di bagian Gas Cutting.

Pengolahan data terdiri dari menggunakan data RULA worksheet untuk mengukur postur kerja dengan cara :

a. membagi pengamatan tubuh operator kedalam 2 grup, yaitu A yang terdiri atas leher (neck), kaki (leg), lengan atas (upper arm), lengan bawah (lower arm), pergelangan tangan (wrist), punggung (trunk), serta mengukur beban (load/force) dan skor aktivitas. Postur tubuh group B terdiri atas leher (neck), batang tubuh (trunk), dan kaki (legs).

b. Menilai setiap postur kerja operator menggunakan Rapid Upper Limb Assessment (RULA) kedalam skor A dan skor B.

c. Menentukan skor RULA dari hasil kombinasi perhitungan skor $\mathrm{A}$ dan skor $\mathrm{B}$.

d. Menentukan action level dari postur kerja operator.

Langkah selanjutnya adalah melakukan analisa dan tindakan yang diperlukan berdasarkan skor RULA yang diperoleh.

\section{HASIL DAN PEMBAHASAN}

Postur kerja operator bagian gas cutting yang diamati adalah postur kerja berpotensi menimbulkan musculoskeletal disorder yaitu kegiatan mengoperasikan panel mesin gas cutting. membersihkan sisi pemotongan menggunakan special tools dan menggerinda sisi plate hasil pemotongan.

Tabel 1. Tabulasi hasil standard nordic questionnaire

\begin{tabular}{clc}
\hline No & \multicolumn{1}{c}{ Jenis Keluhan } & Jumlah \\
\hline 1 & $\begin{array}{l}\text { Sakit kaku pada leher } \\
\text { bagian atas }\end{array}$ & 15 \\
2 & $\begin{array}{l}\text { Sakit pada bahu kanan } \\
3\end{array}$ & 8 \\
4 & $\begin{array}{l}\text { Sakit di punggung } \\
\text { Sakit pada lengan atas }\end{array}$ & 17 \\
$\quad$ kanan & 4 \\
5 & Sakit pada pinggang & 15 \\
6 & Sakit pada bokong & 5 \\
7 & $\begin{array}{l}\text { Sakit pada pergelangan } \\
\text { tangan kanan }\end{array}$ & 2 \\
8 & Sakit pada lutut kiri & 1 \\
9 & Sakit pada lutut kanan & 1 \\
\hline
\end{tabular}

Langkah awal adalah melakukan penyebaran kuesioner nordic questionaire dengan hasil sakit pada punggung merupakan keluhan yang paling banyak dialami (Tabel 1). Berdasarkan keluhan tersebut maka dianalisa posisi kerja untuk mengurangi keluhan operator.

Contoh perhitungan postur kerja operator saat melakukan kegiatan menggerinda hasil pemotongan dengan posisi jongkok adalah sebagai berikut.

a. Postur tubuh Grup A

1. Postur tubuh bagian lengan atas (upper arm) dengan lengan membentuk sudut $20^{\circ}$ diberi skor $=1$ 
2. Postur tubuh bagian lengan bawah (lower arm) dengan lengan bawah membentuk sudut $110^{\circ}$ diberi skor $=2$

3. Postur tubuh bagian pergelangan tangan (wrist) dengan sudut pergelangan tangan pada posisi netral diberi skor $=1$

Putaran pergelangan tangan (wrist twist) dengan putaran pergelangan tangan berada di garis tengah diberi skor $=1$

4. Skor postur kerja group A berdasarkan tabel 2 adalah $=2$

a. skor aktivitas

Aktivitas dilakukan dengan beberapa bagian tubuh diam dengan skor $=1$

b. skor beban

c. Beban $<2 \mathrm{~kg}$ dengan skor $=0$

d. Total skor untuk grup A adalah $2+1=4$

Tabel 2. Skor grup A untuk postur jongkok

\begin{tabular}{|c|c|c|c|c|c|c|c|c|c|}
\hline \multirow{4}{*}{$\begin{array}{c}\text { Upper } \\
\text { arm }\end{array}$} & \multirow{4}{*}{$\begin{array}{c}\text { Lower } \\
\text { arm }\end{array}$} & \multicolumn{8}{|c|}{ Wrist } \\
\hline & & \multicolumn{2}{|c|}{1} & \multicolumn{2}{|c|}{2} & \multicolumn{2}{|c|}{3} & \multicolumn{2}{|c|}{4} \\
\hline & & \multicolumn{2}{|c|}{ Wrist twist } & \multicolumn{2}{|c|}{ Wrist twist } & \multicolumn{2}{|c|}{ Wrist twist } & \multicolumn{2}{|c|}{ Wrist twist } \\
\hline & & 1 & 2 & 1 & 2 & 1 & 2 & 1 & 2 \\
\hline \multirow{3}{*}{1} & 1 & 1 & 2 & 2 & 2 & 2 & 3 & 3 & 3 \\
\hline & 2 & 2 & 2 & 2 & 2 & 3 & 3 & 3 & 3 \\
\hline & 3 & 2 & 3 & 2 & 3 & 3 & 3 & 4 & 4 \\
\hline \multirow{3}{*}{2} & 1 & 2 & 2 & 2 & 3 & 3 & 3 & 4 & 4 \\
\hline & 2 & 2 & 2 & 2 & 3 & 3 & 3 & 4 & 4 \\
\hline & 3 & 2 & 3 & 3 & 3 & 3 & 4 & 4 & 5 \\
\hline \multirow{3}{*}{3} & 1 & 2 & 3 & 3 & 3 & 4 & 4 & 5 & 5 \\
\hline & 2 & 2 & 3 & 3 & 3 & 4 & 4 & 5 & 5 \\
\hline & 3 & 2 & 3 & 3 & 4 & 4 & 4 & 5 & 5 \\
\hline \multirow{3}{*}{4} & 1 & 3 & 4 & 4 & 4 & 4 & 4 & 5 & 5 \\
\hline & 2 & 3 & 4 & 4 & 4 & 4 & 4 & 5 & 5 \\
\hline & 3 & 3 & 4 & 4 & 5 & 5 & 5 & 6 & 6 \\
\hline \multirow{3}{*}{5} & 1 & 5 & 5 & 5 & 5 & 5 & 6 & 6 & 7 \\
\hline & 2 & 5 & 6 & 6 & 6 & 6 & 7 & 7 & 7 \\
\hline & 3 & 6 & 6 & 6 & 7 & 7 & 7 & 7 & 8 \\
\hline \multirow{3}{*}{6} & 1 & 7 & 7 & 7 & 7 & 7 & 8 & 8 & 9 \\
\hline & 2 & 7 & 8 & 8 & 8 & 8 & 9 & 9 & 9 \\
\hline & 3 & 9 & 9 & 9 & 9 & 9 & 9 & 9 & 9 \\
\hline
\end{tabular}

b. Postur tubuh Grup B

1. Postur tubuh bagian leher (neck) membentuk membentuk membentuk sudut $40^{\circ}$ diberi skor $=3$

2. Postur tubuh bagian batang tubuh (trunk) membentuk sudut $80^{\circ}$ dengan skor $=4$

3. Postur tubuh bagian kaki (legs) diberi skor 1
4. Skor postur tubuh Grup B adalah $=2$ (Tabel

3) adalah $=5$

a. skor aktivitas

Aktivitas dilakukan dengan beberapa bagian tubuh diam dengan skor $=1$

b. skor beban

c. Beban $<2 \mathrm{~kg}$ dengan skor $=0$

d. Total skor untuk grup $B$ adalah $5+1=8$

Tabel 3. Skor grup B untuk postur jongkok

\begin{tabular}{|c|c|c|c|c|c|c|c|c|c|c|c|c|}
\hline \multirow[t]{4}{*}{ Neck } & \multicolumn{12}{|c|}{ Trunk posture score } \\
\hline & \multicolumn{2}{|c|}{1} & \multicolumn{2}{|c|}{ 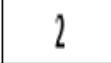 } & \multicolumn{2}{|c|}{3} & \multicolumn{2}{|c|}{4} & \multicolumn{2}{|c|}{5} & \multicolumn{2}{|c|}{6} \\
\hline & \multicolumn{2}{|c|}{ legs } & \multicolumn{2}{|c|}{$\operatorname{leg} 5$} & \multicolumn{2}{|c|}{ leggs } & \multicolumn{2}{|c|}{ leggs } & \multicolumn{2}{|c|}{ legs } & \multicolumn{2}{|c|}{ legs } \\
\hline & 1 & 2 & 1 & 2 & 1 & 2 & 1 & 2 & 1 & 2 & 1 & 2 \\
\hline 1 & 1 & 3 & 2 & 3 & 3 & 4 & 5 & 5 & 6 & 6 & 7 & 7 \\
\hline 2 & 2 & 3 & 2 & 3 & 4 & 5 & 5 & 5 & 6 & 7 & 7 & 7 \\
\hline 3 & 3 & 3 & 3 & 4 & 4 & 5 & (5) & 6 & 6 & 7 & 1 & 7 \\
\hline 4 & 5 & 5 & 5 & 6 & 6 & 1 & 7 & 7 & 7 & 7 & 8 & 8 \\
\hline 5 & 1 & 1 & 7 & 7 & 7 & 8 & 8 & 8 & 8 & 8 & 8 & 8 \\
\hline 6 & 8 & 8 & 8 & 8 & 8 & 8 & 8 & 9 & 9 & 9 & 9 & 9 \\
\hline
\end{tabular}

Tabel 4. Skor grup C untuk postur jongkok

\begin{tabular}{|c|c|c|c|c|c|c|c|}
\hline \multirow{2}{*}{$\begin{array}{c}\text { Score } \\
\text { group A }\end{array}$} & \multicolumn{7}{|c|}{ Score group $B$} \\
\hline 1 & 1 & 2 & 3 & 4 & 5 & 6 & $7+$ \\
\hline 2 & 2 & 2 & 3 & 3 & 4 & 5 & 5 \\
\hline 3 & 3 & 3 & 3 & 4 & 4 & 5 & 6 \\
\hline 4 & 3 & 3 & 3 & 4 & 5 & 6 & 6 \\
\hline 5 & 4 & 4 & 4 & 5 & 6 & 7 & 7 \\
\hline 6 & 4 & 4 & 5 & 6 & 6 & 7 & 7 \\
\hline 7 & 5 & 5 & 6 & 6 & 7 & 7 & 7 \\
\hline+8 & 5 & 5 & 6 & 7 & 7 & 7 & 7 \\
\hline
\end{tabular}

Skor akhir untuk aktivitas menggerinda sisi plate hasil pemotongan adalah $=6$. Berdasarkan skor tersebut maka level resiko dari aktivitas menggerinda sisi plate hasil pemotongan berada pada kategori level risiko sedang dan diperlukan tindakan dalam waktu dekat. Operator menggerinda sisi plate apabila terdapat cutting chip (slag) sisa pemotongan yang menempel 
dengan posisi jongkok. Hal ini disebabkan karena posisi stand untuk menggerinda sangat rendah sehingga dapat beresiko cedera punggung dan leher.

Dengan langkah yang sama maka diperoleh hasil pada kegiatan lainnya adalah Skor akhir untuk aktivitas mengoperasikan mesin dengan posisi duduk adalah $=3$. Berdasarkan skor tersebut maka level resiko dari aktivitas mengoperasikan mesin gas cutting berada pada kategori level risiko kecil dan diperlukan beberapa perbaikan beberapa waktu kedepan. Karena tidak dipasangnya kursi untuk operator saat mengoperasikan panel gas cutting mesin maka operator harus duduk dibawah dengan posisi kepala menengadah ke atas dikarenakan posisi panel yang lebih tinggi dan berisiko menyebabkan nyeri pada leher

Skor akhir untuk aktivitas membersihkan sisi plate hasil pemotongan dengan posisi membungkuk adalah $=5$. Berdasarkan skor tersebut maka level risiko dari aktivitas membersihkan sisi plate hasil pemotongan berada pada kategori level risiko sedang dan diperlukan tindakan dalam waktu dekat. Operator membersihkan sisi plate hasil pemotongan untuk menghilangkan kerak dengan posisi membungkuk. Hal ini disebabkan karena alat bantu untuk membersihkan kerak pada sisi plate hasil pemotongan terlalu pendek sehingga dapat berisiko cedera pada punggung.

Beberapa usaha yang dapat dilakukan untuk mengurangi risiko tersebut antara lain pemasangan kursi pada mesin gas cutting untuk membantu operator saat mengoperasikan panel mesin supaya selama proses berlangsung operator dapat duduk dengan nyaman dan dapat mengoperasikan panel dengan mudah tanpa harus menengadahkan leher dan menjulurkan tangan ke atas. Pembuatan alat bantu untuk membersihkan kerak pada sisi plate hasil pemotongan (special tools) yang lebih panjang sehingga operator tidak perlu membungkuk saat membersihkan kerak hasil pemotongan. Menyediakan bangku kecil untuk membantu operator saat menggerinda plate agar tidak mengalami cedera karena menggerinda dengan posisi jongkok.

\section{KESIMPULAN}

Kesimpulan yang diperoleh berdasarkan hasil analisis yang telah dilakukan adalah keluhan cedera otot tertinggi terdapat pada bagian punggung dengan frekuensi sebanyak 17 orang, kemudian jumlah keluhan pada bagian pinggang sebanyak 15 orang, dan sakit kaku pada leher bagian atas sebanyak 13 orang. Hal tersebut dikarenakan terjadinya kontraksi pada otot sehingga menimbulkan rasa nyeri. Berdasarkan hasil pengolahan data dengan metode RULA dapat disimpulkan bahwa postur kerja yang memiliki level resiko tertinggi pada operator gass cutting adalah saat operator melakukan kegiatan pembersihan kerak hasil pemotongan dimana operator melakukan kegiatan tersebut dengan posisi membungkuk dan hasil perhitungan dengan metoe RULA postur ini memiliki skor akhir 6 yang berarti perlu adanya tindakan dalam waktu dekat. Posisi kerja dari operator yaitu dengan duduk yang tidak nyaman posisi tubuh tidak adanya untuk bersandar bagian punggung atas ini adalah bagian yang peluang terjadi cedera otot pada operator. Untuk mengurangi rasa sakit pada leher, batang tubuh, dan lengan, sebaiknya para operator tidak melakukan postur kerja yang menyebabkan rasa sakit pada bagian tubuh terebut dalam waktu yang lama

\section{DAFTAR PUSTAKA}

Agustina, F., \& Maulana, A. (2012). Analisis postur kerja dengan tinjauan ergonomi di industri batik Madura. Jurnal Inovasi Dan Kewirausahaan, 1(3), 167-171.

Ansari, N. A., \& Sheikh, M. J. (2014). Evaluation of work Posture by RULA and REBA: A Case Study. IOSR Journal of Mechanical and Civil Engineering, 11(4), 18-23.

Budiman, E., \& Setyaningrum, R. (2012). Perbandingan Metode-Metode Biomekanika Untuk Menganalisis Postur Pada Aktivitas Manual Material Handling (MMH) Kajian Pustaka. J@ Ti Undip: Jurnal Teknik Industri, 1(3), 46-52.

Correia, D. F., Yusuf, M., \& Simanjuntak, R. A. (2016). Analisis Postur Kerja Menggunakan Metode Rapid Upper Limb Assessment (RULA) dan Ovako Working Posture Analysis System (OWAS). Jurnal Rekavasi, 4(2), 82-90.

Listiarini, A., Widjasena, B., \& Wahyuni, I. (2016). Hubungan Kekuatan Otot Punggung Dengan Keluhan Nyeri Punggung Pada Porter Di Stasiun Tawang Semarang. Jurnal Kesehatan Masyarakat (e-Journal), 4(4), 636-644.

McAtamney, L., \& Corlett, E. N. (1993). RULA: a survey method for the investigation of workrelated upper limb disorders. Applied Ergonomics, 24(2), 91-99.

Nugraha, H. A., Astuti, M., \& Rahman, A. (2013). Analisis Perbaikan Postur Kerja Operator Menggunakan Metode Rula Untuk Mengurangi Resiko Musculoskeletal Disorders (Studi Kasus pada Bagian Bad Stock Warehouse PT. X Surabaya). Jurnal 
Rekayasa Dan Manajemen Sistem Industri, 1(2), p229-240.

Nuryaningtyas, B. M., \& Martiana, T. (2014).

Analisis Tingkat Risiko Muskuloskeletal

Disorders (MSDs) dengan The Rapid Upper

Limbs Assessment (RULA) dan

Karakteristik Individu Terhadap Keluhan

MSDs. The Indonesian Journal of

Occupational Safety and Health, 3(3), 160169. 